\title{
Of time and the energy wars
}

In another of an occasional series, Alvin M. Weinberg, Director of the Institute for Energy Analysis at Oak Ridge, Tennessee, comments on a difficult trade-off

QUANTUM mechanics tells us that energy and time are conjugate variables. I am therefore much bemused these days by an observation pointed out to me by a young Swiss physicist, Daniel Spreng, that in a certain social sense energy and time are conjugates. What Dr Spreng means by this is simply that man expends energy in order to save time; moreover, when given the choice, he usually chooses to save time over saving energy. (To be more accurate, it is availability rather than energy that is usually meant in these contexts).

This surely was the case during man's early civilisation. Domestic animals did the job quicker, and slaves were acquired because they were a source of intelligent energy. The slave-owner therefore had more freedom of choice in using time than did the peasant who thad to work his field himself. And each technological achievement (at least until the advent of information technology) represented such a trade-off: the industrial revolution, the transportation revolution, the agricultural revolution-always it was man in a hurry ready to spend more energy in order to save time.

Actually this exchange of energy for time has a basis in thermodynamics, despite the well-known fact that thermodynamics never treats time explicitly. In thermodynamics we learn that the minimum free energy is expended when a process, like desalting, is performed reversibly. A reversible process, however, is usually considered to require an infinite amount of time; if we wish to save time, we must expend more energy since the process will then be performed irreversibly. Thus the minimum amount of work required to desalt 1,000 gallons of seawater is $3 \mathrm{kWh}$; the actual amount used in a practical desalting device is ten or more times higher than this.

Heat transfer processes can be performed reversibly in a finite time if the apparatus, particularly the heat transfer surface, is sufficiently large. In that case the temperature drops approach zero, and reversibility is achieved. But we must remember that the total energy required to conduct a process is actually the sum of two energies: the usual energy which is transferred from one body to another: and the energy that went into constructing the apparatus. Ordinarily we ignore the latter. But if the apparatus becomes very large we ought not to ignore this since the energy that went into making the apparatus--the mining and refining of the metal, its frabrication, its transportbecomes very large. Thus the total energy goes through a minimum as the degree of irreversibility diminishes. To perform a task in a finite time requires more energy than to perform it in a longer time, either because we do it irreversibly or because to do it reversibly requires a very large apparatus that itself embodies a great deal of energy.

Though I am bemused by the fact that time and energy can be regarded as conjugates, I do not put this forth as a magical talisman for guiding our course in the great energy debate, but simply as an antidote for the view that thermodynamics can guide energy policy better than can the evolving values of our society, particularly as embodied in economics. This view seems to be promulgated, especially in the United States, by Barry Commoner and Amory Lovins, to mention the most notable. They assert, with truth, that in principle we can save energy if we do a better iob of matching the quality of the heat source with the quality of the heat required to achieve a given end. If water is wanted at $70^{\circ} \mathrm{C}$, why use a flame with a temperature of $1,000^{\circ} \mathrm{C}$ as the heat source? And in two widely read

\section{Sorry, for copyright reasons some images on this page may not be available online}

Time savers, or energy wasters?

articles, Commoner's "The Poverty of Power", which appeared in the New Yorker and then as a book, and Lovins' "Energy Strategy: The Road Not Taken?" which appeared in, of all places, Foreign Affairs, much was made of maximising this 'second law efficiency'. Indeed, the lesson thermodynamics teaches us for energy policy, according to Commoner and to Lovins, is mainly that we must maximise second law efficiency: in so doing we will save energy and creatc the good, that is, decentralised society, not to say eliminate nuclear energy.

But all this is so one dimensional. To be sure energy is a finite good, and we suffer from a shortage of it. But there are other goods that are finite, and of these I would consider time to be the most fundamental. This, I suppose, is one of the prices we pay for our knowledgc of our mortality: we value time because we know it is limited, and we will do much to save it and to expand our choices in using it. If the underlying trade-off is between energy and time, then we mislead if we try to use thermodynamics as a primary guide to energy policy since thermodynamics gives no value to time: it is prepared to speak of processes that are infinitely slow, that ignore man's mortality.

There are those who argue that we have passed the point where energy can be exchanged for time. For example, S. linder in The Harried Leisure Classes points out that our cnergy-intensive technologies themselves rob us of time: to maintain our gadgets, to commutc, to listen to the semantic drivel that our new technologies impose upon us. And I cannot deny the merit of Linder's thesis: the Leisure Class is harried.

Yet who is to judge whether the trade-off between energy and time is to favour energy or time-the energy revolutionaries such as Commoner and Lovins, or the rest of us? We are short of energy, but we are also short of other things, like time. A free society allows each of us to make the choice, to allocate as we each decide. Economics in the broadest sense, integrates all these trade-offs and judgments -it allows us to weigh time against energy, or for that matter, any other good against energy. I would hope the energy revolutionaries could he persuaded to be a little less revolutionary and not reject these homely truisms of engineering economics for a world they would impose on us with their emphasis on thermodynamic analysis. 